\title{
SCIENTIFIC REP RTS OPEN Author Correction: Myeloperoxidase is not a good biomarker for preeclampsia prediction
}

\section{Rocha-Penha' ${ }^{1}$, H. Bettiol ${ }^{2}$, M. A. Barbieri' ${ }^{2}$, V. C. Cardoso ${ }^{2}$, R. C. Cavalli ${ }^{3}$ \& V. C. Sandrim ${ }^{1}$}

Correction to: Scientific Reports https://doi.org/10.1038/s41598-017-09272-4, published online 31 August 2017

The Acknowledgements section in this Article is incomplete.

"The authors acknowledge the Conselho Nacional de Desenvolvimento Científico e Tecnológico (CNPq-Brazil), the Coordenação de Aperfeiçoamento de Pessoal de Nível Superior (CAPES-Brazil), and the Fundação de Amparo à Pesquisa do Estado de São Paulo (FAPESP-Brazil) for financial help, as well as the team involved in BRISA study."

should read:

"The authors acknowledge the Conselho Nacional de Desenvolvimento Científico e Tecnológico (CNPq-Brazil; grant \#2014-5/305587), the Coordenação de Aperfeiçoamento de Pessoal de Nível Superior (CAPES-Brazil), and the Fundação de Amparo à Pesquisa do Estado de São Paulo (FAPESP-Brazil grants \#2017/14546-6, \#2015/20461-8 and \#2008/53593-0) for financial help, as well as the team involved in BRISA study."

(i) Open Access This article is licensed under a Creative Commons Attribution 4.0 International License, which permits use, sharing, adaptation, distribution and reproduction in any medium or format, as long as you give appropriate credit to the original author(s) and the source, provide a link to the Creative Commons license, and indicate if changes were made. The images or other third party material in this article are included in the article's Creative Commons license, unless indicated otherwise in a credit line to the material. If material is not included in the article's Creative Commons license and your intended use is not permitted by statutory regulation or exceeds the permitted use, you will need to obtain permission directly from the copyright holder. To view a copy of this license, visit http://creativecommons.org/licenses/by/4.0/.

(c) The Author(s) 2018

\footnotetext{
${ }^{1}$ Department of Pharmacology, Institute of Biosciences of Botucatu, Universidade Estadual Paulista (UNESP), Distrito Rubiao Junior, Botucatu, São Paulo, 18680-000, Brazil. ${ }^{2}$ Department of Pediatrics, Faculty of Medicine of Ribeirao Preto, University of Sao Paulo, Ribeirao Preto, Sao Paulo, 14049-900, Brazil. ${ }^{3}$ Department of Gynecology and Obstetrics, Faculty of Medicine of Ribeirao Preto, University of Sao Paulo, Ribeirao Preto, São Paulo, 14049-900, Brazil. Correspondence and requests for materials should be addressed to V.C.S. (email: valeria.sandrim@ibb.unesp.br)
} 